\title{
Effect of Blast Wave on Structures
}

\author{
Anuj Kumar ${ }^{1}$, Gaurav Kumar ${ }^{2}$ \\ ${ }^{1}$ M.Tech. Student, Department of Civil Engineering, NNSS SAmalkha Group of Institutions, Department of Civil Engineering, Affiliated to \\ Kurukshetra University, Kurukshetra, Haryana, India
}

${ }^{2}$ HOD, Department of Civil Engineering, NNSS SAmalkha Group of Institutions, Department of Civil Engineering, Affiliated to Kurukshetra University, Kurukshetra, Haryana, India

\begin{abstract}
In recent years, explosive devices are the weapon of choices for the majority of terrorist attack that not only affects the life of human being but also the structure resistance and physical integrity. Bomb explosion near the building can cause such amount of pressure and produces a large amount of heat resulting a high strain loading on building and its elements. Such a high strain loading can cause catastrophic damage on building's external and internal structural frame, collapsing of walls, blowing out large expense of windows and shutting down of critical life safety systems. The response of steel frame building subjected to blast loading was examined by calculating blast load manually using a procedure and applying on joints. Response of steel column subjected to amount of pressure exerted by different charge weights and at different standoff distance and progressive energy collapse of steel column is examined using Ansys Explicit dynamic and Ansys Autodyn. Concrete wall subjected to blast loading is modeled in Finite Element package Ansys and then analyzed in Autodyn with and without steel plate to study the impact of blast loading.
\end{abstract}

Keywords: Blast loading, Sap 2000,Autodyn

\section{Introduction}

In the past few decades terrorist attacks and threats are the growing problem all over the world that not only affects the life of human being but also the structural resistance and its physical integrity. Also considerable emphasis has been given to problems of blast and earthquake. The earthquake problem is rather old, but most of the study and knowledge on this subject has been accumulated during the past sixty years. The blast problem is rather new; information about the development in this field is made available mostly through publication of the army Corps of Engineers, Department of Defence, public institutes and other governmental office. Due to different accidental or intentional events, the behaviour of structural components subjected to blast loading has been the subject of considerable research effort in recent years. Conventional structures, particularly that above grade, normally are not designed to resist blast loads; and because the magnitudes of design loads are significantly lower than those produced by most explosions, conventional structures are susceptible to damage from explosions. With this in mind, developers, architects and engineers increasingly are seeking solutions for potential blast situations, to protect building occupants and the structures

Disasters such as the terrorist bombings of the U.S. embassies in Nairobi, Kenya and Dares Salaam, Tanzania in 1998, the Khobar Towers military barracks in Dhahran, Saudi Arabia in 1996, the Murrah Federal Building in Oklahoma City in 1995, and the World Trade Centre in New York in 1993 have demonstrated the need for a thorough examination of the behaviour of columns subjected to blast loads (Kirk, et al., 2005). To provide adequate protection against explosions, the design and construction of public buildings are receiving renewed attention of structural engineers. Difficulties that arise with the complexity of the problem, which involves time dependent finite deformations, high strain rates, and non-linear inelastic material behaviour, have motivated various assumptions and approximations to simplify the models. These models span the full range of sophistication from single degree of freedom systems to general purpose finite element programs such as ABAQUS, ANSYS, and ADINA etc.

\section{Background}

The study and analysis of the blast loading on the structure started in $1960^{\circ e}$ s. US Department of the Army, released a technical manual titled "structures to resist the effects of accidental explosions" in 1959. The revised edition of the manual TM 5-1300 (1990) most widely used by military and civilian organization for designing structures to prevent the propagation of explosion and to provide protection for personnel and valuable equipments.

Following methods are available for prediction of blast effects on buildings structures i.e.

- Empirical (or analytical) methods

- Semi-empirical methods

- Numerical methods

Empirical methods are essentially correlations with experimental data. Most of these approaches are limited by the extent of the underlying experimental database. The accuracy of all empirical equations diminishes as the explosive event becomes increasingly near field.

Semi-empirical methods, which are based on simplified models of physical phenomena. The attempt is to model the underlying important physical processes in a simplified way. These methods are dependent on extensive data and case study. The predictive accuracy is generally better than that provided by the empirical methods.

Numerical (or first-principle) methods are based on mathematical equations that describe the basic laws of physics governing a problem. These principles include conservation of momentum, energy, and mass. In addition, the physical behaviour of materials is described by 


\section{International Journal of Science and Research (IJSR) \\ ISSN (Online): 2319-7064}

Index Copernicus Value (2013): 6.14 | Impact Factor (2015): 6.391

constitutive relationships. These models are commonly termed computational fluid dynamics (CFD) models.

The key elements are the loads produced from explosive sources, how they interact with structures and the way structures respond to them. Explosive sources include gas, high explosives, nuclear and dust materials. The basic features of the explosion and blast wave phenomena are presented along with a discussion of TNT (trinitrotoluene) equivalency and also studied the dynamic response of a steel structure to the blast loading and shows the behaviour of ductile steel column and steel connections for the blast loads.

M. V. Dharaneepathy et al. (1995) studied the effects of the stand-off distance on tall shells of different heights, carried out with a view to study the effect of distance (ground-zero distance) of charge on the blast response. An important task in blast- resistant design is to make a realistic prediction of the blast pressures. The distance of explosion from the structure is an important datum, governing the magnitude and duration of the blast loads. The distance, known as ,critical ground-zero distance ${ }^{e e}$, at which the blast response is a maximum. This critical distance should be used as design distance, instead of any other arbitrary distance.

Ronald L. Shope (2006) studied the response of wide flange steel columns subjected to constant axial load and lateral blast load. The finite element program ABAQUS was used to model with different slenderness ratio and boundary conditions. Non-uniform blast loads were considered. Changes in displacement time histories and plastic hinge formations resulting from varying the axial load were examined.

T. Borvik et al. (2009) studied the response of a steel container as closed structure under the blast loads. He used the mesh less methods based on the Lagrangian formulations to reduce mesh distortions and numerical advection errors to describe the propagation of blast load. All parts are modelled by shell element type in LS- DYNA. A methodology has been proposed for the creation of inflow properties in uncoupled and fully coupled Eulerian- Lagrangian LSDYNA simulations of blast loaded structures.

TM 5-1300 (UFC 3-340-02, 1990) is a manual titled "structures to resist the effects of accidental explosions" which provides guidance to designers, the step-to-step analysis and design procedure, including the information on such items (1) blast, fragment and shock loading. (2) principle on dynamic analysis. (3) reinforced and structural steel design and (4) a number of special design considerations.

T. Ngo, et al. (2007) for their study on "Blast loading and Blast Effects on Structures" gives an overview on the analysis and design of structures subjected to blast loads phenomenon for understanding the blast loads and dynamic response of various structural elements. This study helps for the design consideration against extreme events such as bomb blast, high velocity impacts.

\section{Material Used for Study}

- To study the dynamic response of various structural elements like column, wall in FE program ANSYS Autodyn ${ }^{\circledR}$ by modelling blast with JWL (Jones-WilkinsLee) equation of state.

- To study analytically the structural behaviour of steel column and concrete wall subjected to blast loading All the computations for dynamic loading on a steel structure to evaluate the blast pressure, using Kinney and Graham ${ }^{\text {ee }}$ s approach.

- Computation of the blast loads on the structural joints from peak reflected pressure.

- Modelling of a steel column and concrete wall of different shapes in ANSYS Autodyn .

- Computation of response parameters of the steel column and concrete wall under the blast loading

\section{Test Program}

Height of burst refers to aerial attacks. It is the direct distance between the exploding weapon in the air and the target.

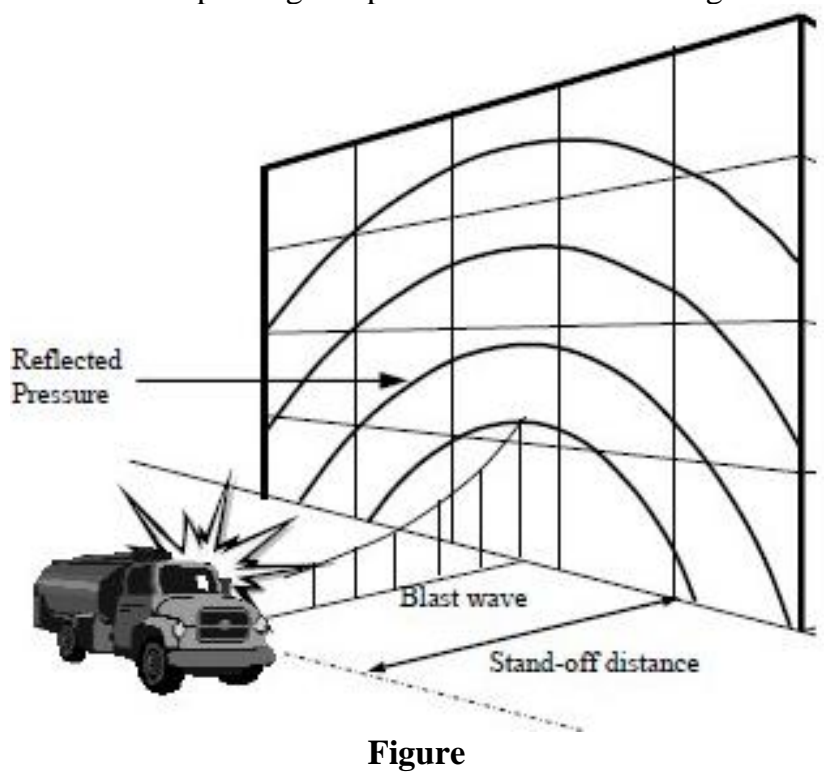

The mechanical properties of concrete under dynamic loading conditions can be quite different from that under static loading. While the dynamic stiffness does not vary a great deal from the static stiffness, the stresses that are sustained for a certain period of time under dynamic conditions may gain values that are remarkably higher than the static compressive strength (Figure 3.8). Strength magnification factors as high as 4 in compression and up to 6 in tension for strain rates in the range: 103-103/sec have been reported (Grote et al., 2001). 


\section{International Journal of Science and Research (IJSR) \\ ISSN (Online): 2319-7064}

Index Copernicus Value (2013): 6.14 | Impact Factor (2015): 6.391

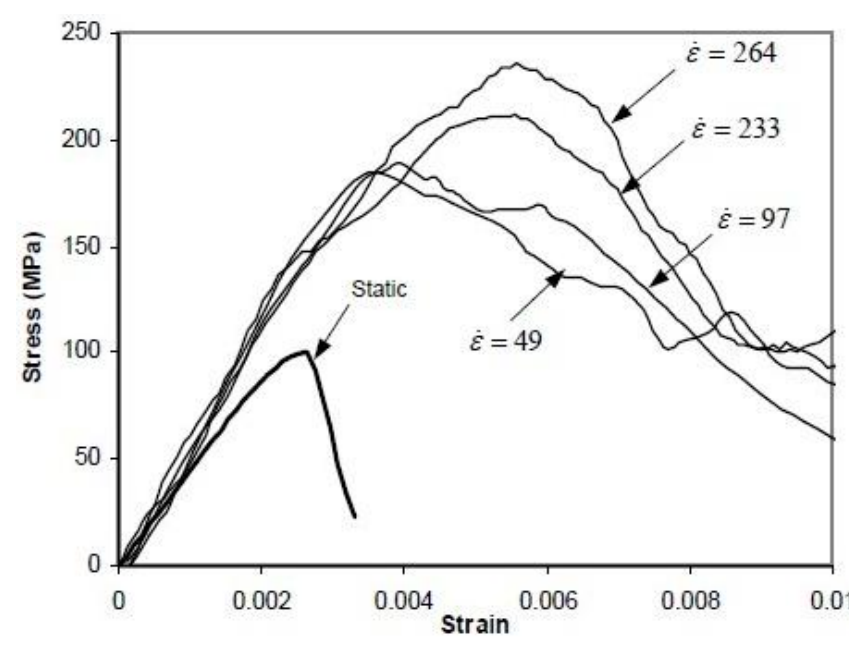

The steel framed structure which has been considered for blast loading is taken from "Energy flow in progressive collapse of steel framed building" by Stefan Szyniszewski. This is a typical low rise steel building in the USA. All prevailing requirements for gravity, wind, and seismic design have been considered. It was designed for a typical office occupancy live load of $2.5 \mathrm{kPa}$. The floors were assumed to support a dead load of $4 \mathrm{kPa}$, which included a concrete-steel composite slab, steel decking, ceilings/ flooring/fireproofing, mechanical/electrical/plumbing systems and partitions (1 $\mathrm{kPa}$ ). The framing plan of the investigated 3-story building is shown in Fig. Column schedules and beam designation are given in Table with designations in AISC

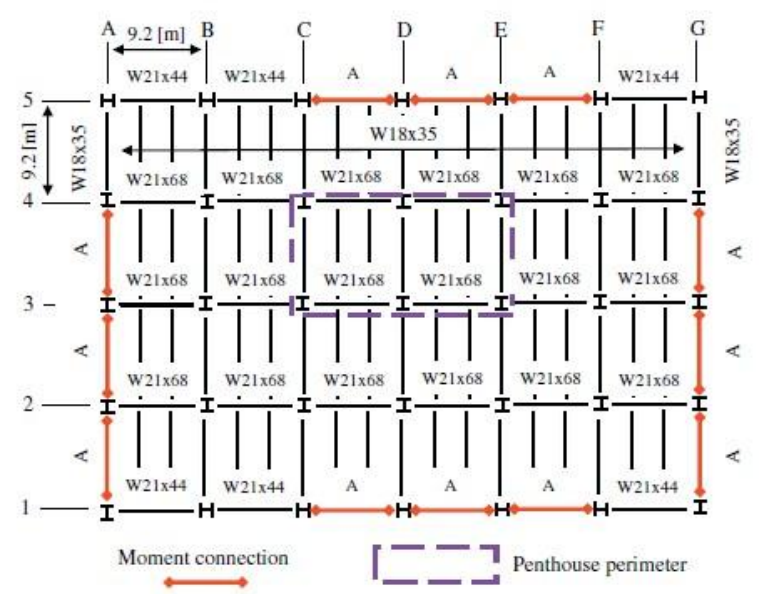

\section{Result and Discussion}

Autodyn

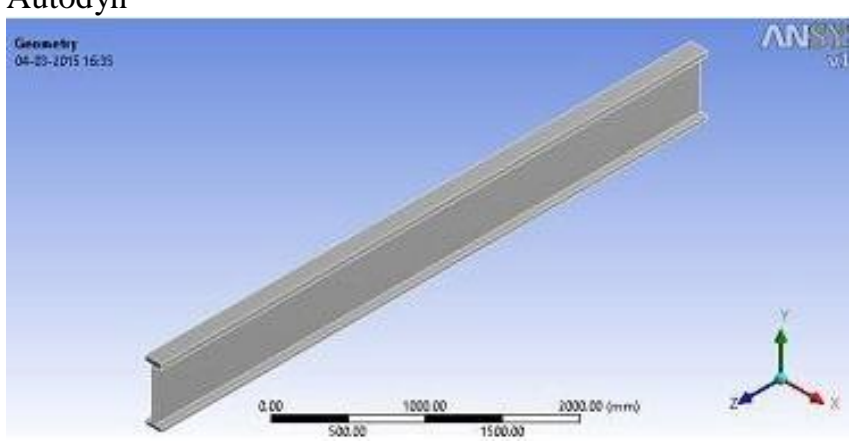

Geometric Model of Steel Colum in ANSYS/Autodyne
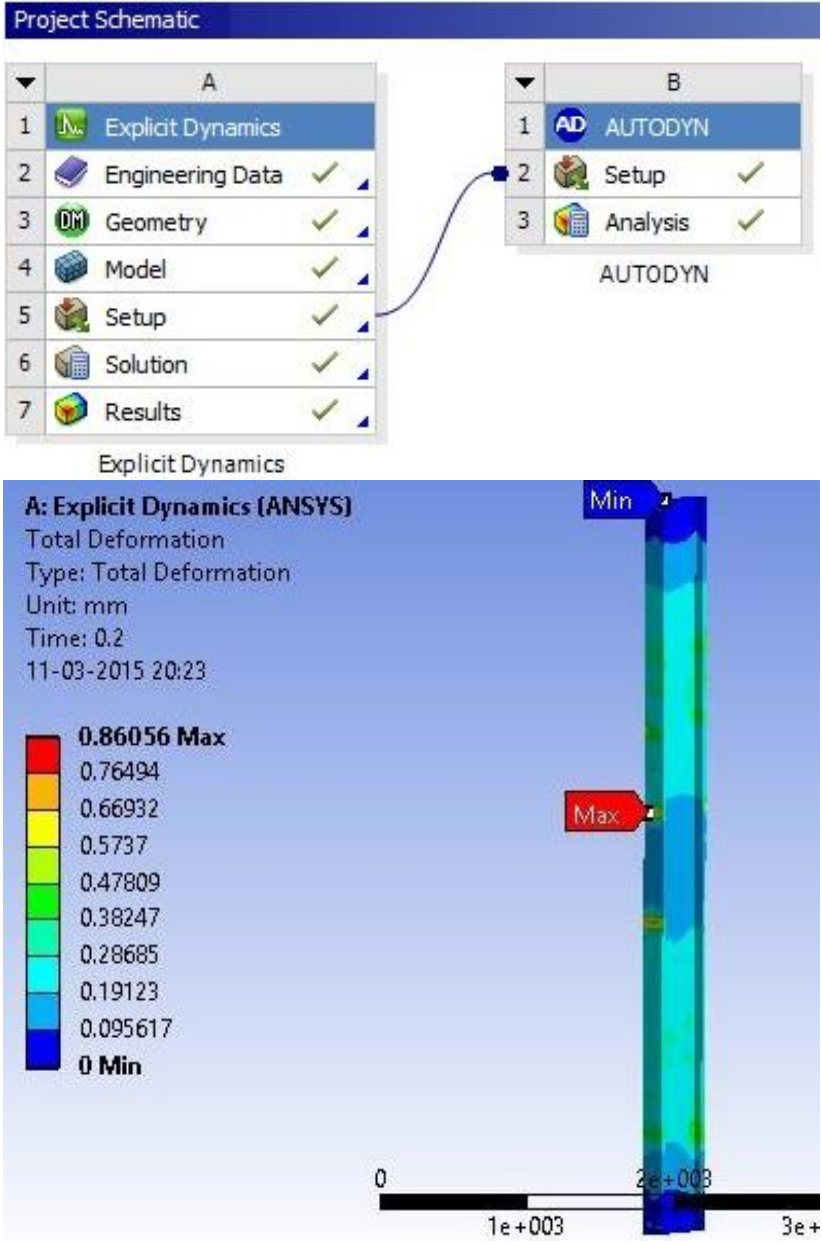

FE Modeler: The model imported from design modeler is transferred to workbench which then attach to FE modeler for meshing and analysis. The model is meshed using tetrahedron element with lagrangian setting using finer mesh. The fixed boundary is applied to bottom surfaces of columns and walls. Model is set with intial condition zero velocities are applied. Superstructure load is estimated and applied as uniformely distributed load on beams and point load on columns. The standard gravity load is applied to model. The analysis is run for 1second and workbench envirnoment is updated for exporting upstream data to Maximum Deformation

\section{Conclusion}

It is observed from literature survey that for the estimation of blast load or pressure the empirical approach (Kinney and Graham "es) proves to be ideal as blast phenomenon is complex in nature. Complexity arises due to unpredictability of charge weight and standoff distance, the behaviour of material under different loading conditions and post blast trigerring events. Ansys Autodyn is an efficient and user friendly tool for simulating eplosives and impact loading linking it with workbench envirnoment. The blast simulation was carriout using JWL as equation of state for explosive materials. The two storey steel structure was subject to singel charge weights and standoff distances to obtain output parameters like, deflection and joint reactions using SAP2000. A steel column from the above structure is

Volume 5 Issue 6, June 2016 www.ijsr.net 


\section{International Journal of Science and Research (IJSR) \\ ISSN (Online): 2319-7064 \\ Index Copernicus Value (2013): 6.14 | Impact Factor (2015): 6.391}

subjected to different charge weight and standoff distance to obtain the parameter like total deformation, maximum principal stress and maximum principal starin and the same column is analysed in Aotudyn to obtain the progressive energy collapse of steel. The concrete walls of different shapes shapes with or without steel plates cladded are analysed in Autodyn to obtain pressure contours and pressure time history plots to study the behaviour and effect of using steel. From the present study the following observations and conclusions are drawn.

1) Blast load on structure cause formation of high reactions on joints leads to shear collapse of joints and total collapse of structure.

2) Analysis of steel column in ANSYS Explicit dynamics clearly specifies that effect of explosion largely depends upon the standoff distance and charge weight.

3) Large deformation is obtained at higher charge weight for a given same standoff distance as evident from graph.

4) Higher stresses have been observed with higher charge weight then with the lower charge weights as evident from table and graph.

5) The finite element analysis revealed that, for axially loaded columns, there exists a critical lateral blast impulse. Any applied blast impulse above this value will result in the collapsing of the column before the allowable beam deflection criterion is reached.

6) For higher charge weights, the collapse occurs faster, as is evident from the graphs. The column fails in half the time for $50 \mathrm{~kg}$ TNT than for $20 \mathrm{~kg}$ TNT, whereas for $100 \mathrm{~kg}$ TNT, it takes about one-fourth the time to fail than $20 \mathrm{~kg}$ TNT.

7) In case of $20 \mathrm{~kg}$ TNT blast, the internal energy of the steel column reduces after about $0.35 \mathrm{~ms}$ of loading, while no reduction in thisenergy is seen for charge weights beyond this value. This occurs prior to failure starts.

8) For $20 \mathrm{~kg}$ and $50 \mathrm{~kg}$ charge weights, the internal energy remains beyond kinetic energy until failure starts, while for $100 \mathrm{~kg}$ charge weights, both the energies remain approximately the same. This may be attributed to the very high impulse pressure of shock waves for higher TNT weights.

9) Autodyn Simulation gave good estimate of pressure time history of observed positive and negative phase.

10) Pressure contour and time history plots signify that using a steel plate reduces the effect of blast pressure on the concrete wall thus reducing the damage due to pressure created by the $100 \mathrm{~kg}$ TNT with standoff distance and height of $3 \mathrm{~m}$ and $1 \mathrm{~m}$. Similar observation goes for other plan shapes.

\section{References}

[1] A. Khadid et al. (2007), " Blast loaded stiffened plates" Journal of Engineering and Applied Sciences, Vol. 2(2) pp. 456-461.

[2] A.K. Pandey et al. (2006) "Non-linear response of reinforced concrete containment structure under blast loading" Nuclear

[3] Engineering and design 236. pp.993- 1002.

[4] Alexander M. Remennikov, (2003) "A review of methods for predicting bomb blast effects on buildings",
Journal of battlefield technology, vol 6, no 3. pp 155161.

[5] American Society for Civil Engineers 7-02 (1997), "Combination of Loads",pp 239-244.

[6] ANSYS Theory manual, version 5.6,200.

[7] Biggs, J.M. (1964), "Introduction to Structural Dynamics", McGraw- Hill, New York.

[8] D.L. Grote et al. (2001), "Dynamic behavior of concrete at high strain rates and pressures", Journal of Impact Engineering, Vol. 25, Pergamon Press, NewYork, pp. 869- 886, 10. IS 456:2000 Indian Standard Plain and Reinforced Concrete Code of Practice.

[9] J.M. Dewey (1971), "The Properties of Blast Waves Obtained from an analysisof the particle trajectories", Proc. R. Soc. Lond. A.314, pp. 275- 299.

[10] J.M. Gere and S.P. Timoshenko (1997.), "Mechanics of materials", PWS publishing company, Buston, Massachusetts, 66.

[11] Kirk A. Marchand, Farid Alfawakhiri (2005), "Blast and Progressive Collapse" fact for Steel Buildings, USA.

[12] M. V. Dharaneepathy et al. (1995), "Critical distance for blast resistance design", computer and structure Vol. 54, No.4.pp.587-595.

[13] Nelson Lam et al. (2004), "Response Spectrum Solutions for Blast Loading", Journal of Structural Engineering, pp 28-44

\section{Author Profile}

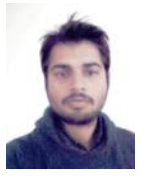

Anuj Kumar is Currently in final year M.TECH Structural Engineering from Samalkha Group of Instutions, Affilated to Kurukshetra University, Kurushetra. He did B.TECH in Civil Engineering from NC College of engineering israna Affilated to Kurushetra University KUK.2013 (2009 Batch). He has I International Publications. His interested areas of research are, blasr waves, medium waves, impact of impulse on concrete. 